\title{
Perioperative Takotsubo Syndrome R Broken Heart Syndrome
}

\author{
Mohammed Amine Ktiri*, Sofia Kaddaf, Adolphe Kasango, Pascal Goube
}

Sud Francilien Hospital, Cardiology Unit, Corbeil-Essonnes, France

DOI: $\underline{10.36347 / \text { sjmcr.2020.v08i07.015 }}$

| Received: 08.07.2020 | Accepted: 15.07.2020 | Published: 28.07 .2020

*Corresponding author: Mohammed Amine Ktiri

Abstract

Takotsubo syndrome, stress-related cardiomyopathy, or broken heart syndrome is a transient cardiomyopathy that was first described in Japan: it generally lasts two weeks, in the absence of mortality or severity at acute phase. Several cases of Takotsubo have been reported worldwide. We report 7 cases of patients treated immediately after surgery for clinical manifestations of chest pain or acute dyspnea with electrical changes to the ECG, elevation of troponins and echocardiographic anomalies thus simulating an acute coronary syndrome. The diagnosis is retained by ultrasound, the coronary angiography does not show any significant lesion and the ventriculography confirms the appearance of the disease. The clinical and ultrasound evolution is favorable with bêta-blockers and ACE inhibitors.

Keywords: Takotsubo, cardiomyopathie, cardiomyopathy, ACE inhibitors.

Copyright @ 2020: This is an open-access article distributed under the terms of the Creative Commons Attribution license which permits unrestricted use, distribution, and reproduction in any medium for non-commercial use (NonCommercial, or CC-BY-NC) provided the original author and source are credited.

\section{INTRODUCTION}

Stress cardiomyopathy is a cardiac syndrome with transient left ventricular dysfunction that has been reported worldwide for the past three decades. The typical appearance of the left ventricle bloated at the end of systole during the acute phase, similar to the pots used by the ancient Japanese octopus fishermen, gave it its name: Tako-Tsubo syndrome characterized by apical ballooning of the left ventricle. The triggers for TakoTsubo syndrome can be physiological or psychological, including shock and emotional stress responsible for acute heart syndrome with reversible heart failure.

In the perioperative period, this syndrome is characterized by a situation leading to intense sympathetic stimulation which can lead, among other things, to an alteration of consciousness, ventricular rhythm disturbances with sometimes acute edema of the lung or cardiocirculatory arrest.

\section{Patients and Methods}

This retrospective study was conducted at the Cardiology Unit of Sud Francilien Hospital during a period of 6 months (November 2019 to April 2020).

\section{ReSUlTS}

All patients were women with an average age of 75.23 years hospitalized in the orthopedic unit and visceral surgery with a clinical presentation in the form of acute chest pain (2 cases), acute dyspnea (4cases) and atrial fibrillation (1case).

Cardiovascular management consisted of initially eliminating a pulmonary embolism and then an exploration of ischemic heart disease by performing an ECG, assay of cardiac enzymes and an echocardiography (Table-1).

Table-1: Clinical, Biological and echographic presentation

\begin{tabular}{|l|l|l|l|l|l|l|}
\hline & AGE & Clinical situation & CPK & Troponin & Akinetic site & LVEF \\
\hline CASE 1 & 83 & Visceral surgery & $(-)$ & $36 \mu \mathrm{g} / \mathrm{L}$ & Mediventricular & $55 \%$ \\
\hline CASE 2 & 79 & Appendicectomy & $(-)$ & $29 \mu \mathrm{g} / \mathrm{L}$ & Apical & $58 \%$ \\
\hline CASE 3 & 85 & cholecystectomy & $(-)$ & $127 \mu \mathrm{g} / \mathrm{L}$ & Mediventricular & $48 \%$ \\
\hline CASE 4 & 71 & cholecystectomy & $(-)$ & $309 \mu \mathrm{g} / \mathrm{L}$ & Apical & $62 \%$ \\
\hline CASE 5 & 69 & visceral surgery & $(-)$ & $65 \mu \mathrm{g} / \mathrm{L}$ & Apical & $65 \%$ \\
\hline CASE 6 & 75 & Orthopedic surgery & $123 \mathrm{UI} / \mathrm{L}$ & $345 \mu \mathrm{g} / \mathrm{L}$ & Apical & $45 \%$ \\
\hline CASE 7 & 65 & Orthopedic surgery & $210 \mathrm{UI} / \mathrm{L}$ & $201 \mu \mathrm{g} / \mathrm{L}$ & Apical & $42 \%$ \\
\hline
\end{tabular}


A coronary angiography was carried out in all the patients showing no significant lesion. A ventriculography comforted the diagnosis of Cardiomyopathy of stress by objectifying evocative kinetic disorders (Figures 1 and 2).
All the patients were put on Beta-blockers, $\mathrm{ACE}$ and Aspirin after agreement of the surgeon.

The outcome was favorable for the 7 cases with complete recovery from left ventricular dysfunction after echocardiographic control at 4 weeks.

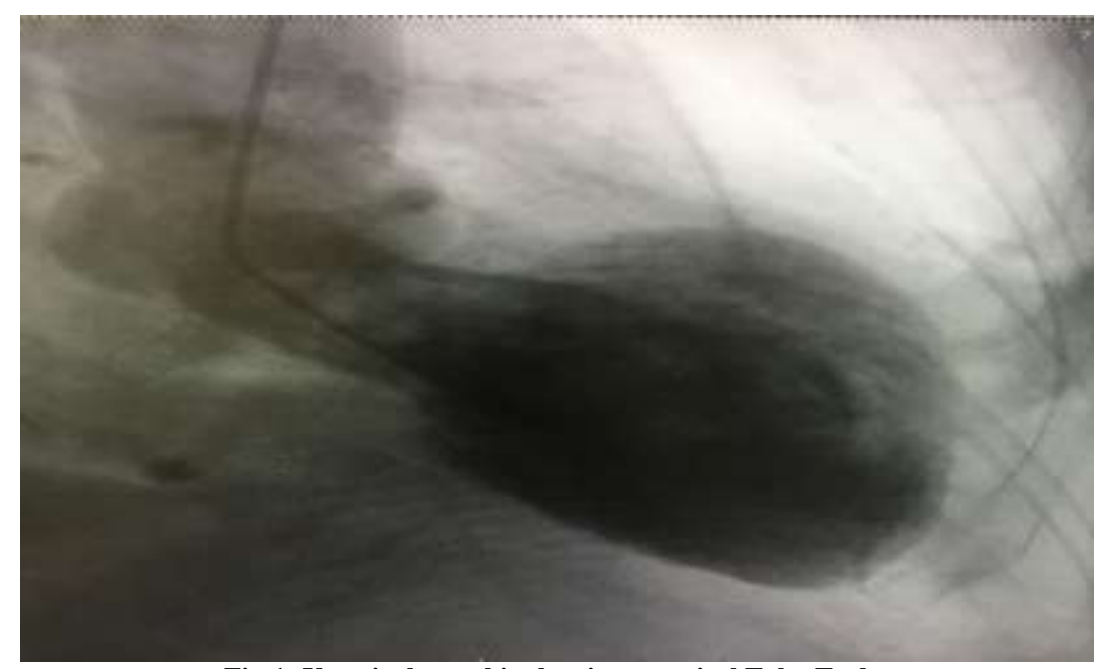

Fig-1: Ventriculographie showing an apical Taku Tsubo

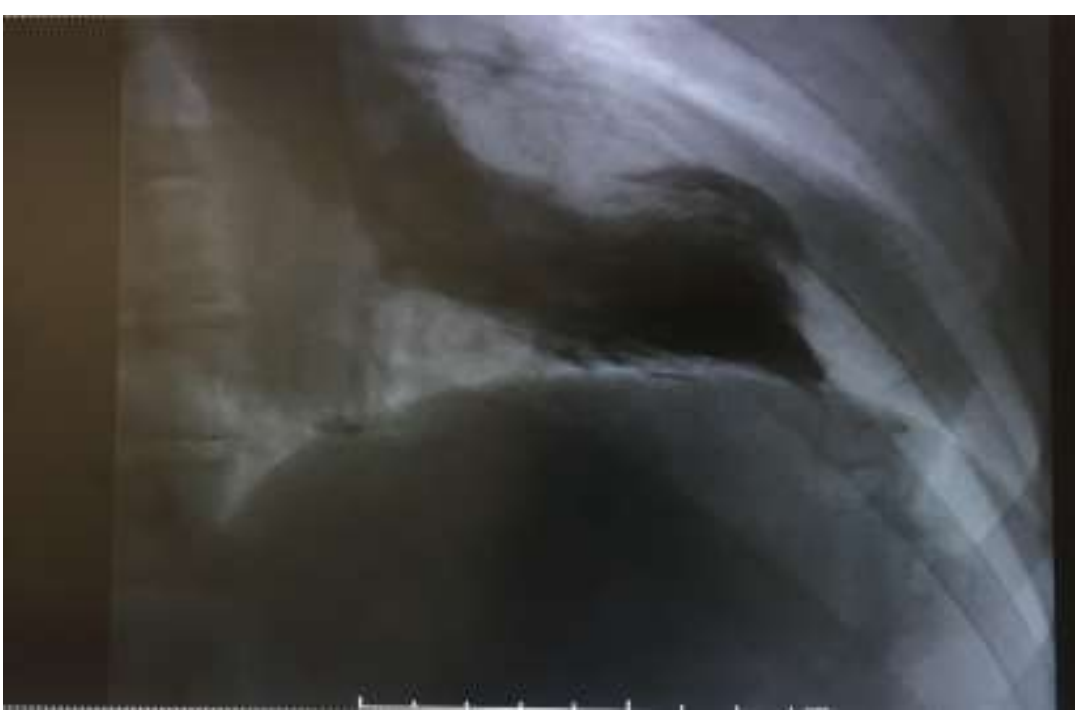

Fig-2: Ventriculographie showing a medioventricular Taku Tsubo

\section{DISCUSSION}

Tako-Tsubo syndrome is a relatively rare myocardial pathology. The prevalence is estimated between 0.5 and $2 \%$ of acute coronary syndromes [1-3]. It is an entity that mainly affects postmenopausal women, exposed to intense physical stress (acute illness, surgery, pain) or more often emotional (bereavement, major fright). Until today, the pathophysiological mechanisms of this syndrome are poorly understood. Furthermore, it is estimated that a significant release of catecholamines into the bloodstream during emotional stress and myocardial hypersensitivity to these catecholamines could explain myocardial damage [4]. Studies have reported an accumulation of glycogen in cardiomyocytes as well as reversible structural alterations in contractile proteins and the cytoskeleton [5].

The clinical presentation can simulate in any point an acute coronary syndrome and associates chest pain, dyspnea, and sometimes syncope or sudden death [2]. The electrocardiogram also shows signs suggestive of an acute coronary syndrome with an over or under shift of the ST segment [2]. The echocardiographic aspect highlights a hypo- or a non-systematic akinesia of the apex of the left ventricle [2]. On the other hand, the contractility of the base of the heart is normal or even most often increased, which can then constitute a dynamic obstacle in terms of the ejection of the ejection chamber from the left ventricle. It is in the absence of coronary lesion on the coronary angiography and the 
typical ultrasound aspect that we must then evoke the diagnosis of Tako-Tsubo syndrome. Contractile anomalies mainly affecting the medio-ventricular segments and respecting the tip may be seen, producing an atypical aspect of the disease [3].

Blood troponin levels are most often normal or discreetly increased. BNP is sometimes high, especially as patients show signs of acute heart failure.

Initial therapeutic management requires rapid coronary angiography to exclude an acute coronary syndrome linked to coronary involvement.

Sometimes the clinical course can go towards a cardiogenic shock which indicate introducing of catecholamines. However, ultrasound should be monitored in this case for the absence of intraventricular obstruction. A counterpulsation balloon can also be used or even ECMO-type circulatory assistance in the event of worsening of cardiogenic shock despite optimal medical treatment. In the absence of signs of cardiogenic shock, beta-blockers reduce dynamic intraventricular obstruction and prevent possible ventricular rhythm disturbances associated with the pathology.

Perioperative management of TCM involves an intricate interplay of several key factors. Elective procedures in patients with known TCM are often delayed until resolution of the cardiomyopathy. If psychological risk factors, have been identified during the preoperative assessment, then delaying an elective surgery may be prudent. For nonelective cases, extra focus on allaying anxiety and stress may help in preventing a TCM episode. If feasible, regional anesthesia with appropriate sedation should be employed since it affords the ability to avoid general anesthesia-associated stress and provides postoperative pain control [6]. Irrespective of the anesthetic management employed, avoidance of stressors that could trigger a catecholamine surge is vital through appropriate pain management and preoperative anxiolysis as well as smooth induction and emergence. Prophylactic bêta-blocker therapy should be given [7]

Outside the acute phase, it is advisable to continue beta-blocking treatment for a few weeks in the absence of contraindications. A converting enzyme inhibitor treatment is sometimes combined for a few weeks.

The evolution of this pathology is most often favorable with a hospital mortality of less than $10 \%[8$, 9].

\section{CONCLUSION}

Stress cardiomyopathy is a clinical entity which must be brought up in the presence of acute coronary syndromes without significant coronary involvement and with transient left ventricular dysfunction. Even retrospective diagnosis can have an impact on the prognosis, thus allowing the discontinuation of drugs which can be harmful in patients most often fragile.

\section{ABBreViations}

ACE: angiotensin-converting enzyme

ECG: Electrocardiogram

TCM: TakoTsubo Cardimyopathy

\section{REFERENCES}

1. Gianni M, Dentali F, Grandi AM, Sumner G, Hiralal R, Lonn E. Apical ballooning syndrome or Tako-Tsubo cardiomyopathy: a systematic review. Eur Heart J. 2006; 27:1523-9.

2. Tsuchihashi K, Ueshima K, Uchida T, Oh-mura N, Kimura K, Owa M, Yoshiyama M, Miyazaki S, Haze K, Ogawa H, Honda T. Transient left ventricular apical ballooning without coronary artery stenosis: a novel heart syndrome mimicking acute myocardial infarction. Journal of the American College of Cardiology. 2001 Jul $1 ; 38(1): 11-8$.

3. Nef HM, Mollmann H, Elsasser A. Tako-Tsubo cardiomyopathy (apical ballooning). Heart. 2007; 93:1309-15.

4. Wittstein IS, Thiemann DR, Lima JA, Baughman KL, Schulman SP, Gerstenblith G, Wu KC, Rade JJ, Bivalacqua TJ, Champion HC. Neurohumoral features of myocardial stunning due to sudden emotional stress. New England Journal of Medicine. 2005 Feb 10;352(6):539-48.

5. Nef HM, Möllmann H, Kostin S, Troidl C, Voss S, Weber M, Dill T, Rolf A, Brandt R, Hamm CW, Elsässer A. Tako-Tsubo cardiomyopathy: intraindividual structural analysis in the acute phase and after functional recovery. European heart journal. 2007 Oct 1;28(20):2456-64.

6. Liu S, Bravo-Fernandez C, Riedl C, Antapli M, Dhamee MS. Anesthetic management of takotsubo cardiomyopathy: General versus regional anesthesia. J Cardiothorac Vasc Anesth. 2008; 22:438-41.

7. Agarwal S, Sanghvi C, Odo N, Castresana MR. Perioperative takotsubo cardiomyopathy: Implications for anesthesiologist. Annals of cardiac anaesthesia. $2019 \mathrm{Jul} ; 22(3): 309-315$.

8. Leyer F, Nallet O, Cattan S. Le syndrome de takotsubo ou ballonisation apicale transitoire du ventricule gauche. InAnnales de cardiologie et d'angeiologie 2008 Nov 1 (Vol. 57, No. 5, pp. 284 289). Elsevier Masson.

9. De Gregorio C, Grimaldi P, Lentini C. Left ventricular thrombus formation and cardioembolic complications in patients with Takotsubo-like syndrome: A systematic review. Int $\mathrm{J}$ Cardiol. 2008;131:18-24. 